$18 q-$ can be expected ${ }^{4}$ Transmission of the disorder from parent to child has been reported ${ }^{5}$ but most cases are mutations.

We know of two reports of children with chromosome 18 deletions and growth hormone deficiency, ${ }^{2}{ }^{3}$ but most authors do not measure growth hormone concentrations. There are reports of primary hypoparathyroidism and primary hypothyroidism, but none of gonadotrophin deficiency though some boys have small penises and testicles.

A causal association between growth hormone deficiency and 18 chromosome deletion is difficult to justify, as the gene for growth hormone production seems to lie on chromosome 17. Our patient was resuscitated in the neonatal period and perinatal asphyxia causing hypothalamic damage cannot be ruled out as the cause. His brain scan was normal so that there was no gross anatomical cerebral abnormality, but the pituitary sella was abnormally small.

Three reports of growth hormone deficiency in a comparatively rare chromosome disorder suggest that hypopituitarism should be sought for in children with this chromosome deletion and short stature. Some children seen in growth clinics are dysmorphic, or have minor or major chromosome abnor- malities, and usually paediatricians regard these children's short stature as part of their particular disorder. This case emphasises the need to measure growth hormone concentrations if height velocity is decreasing or retardation of growth is severe.

\section{References \\ ${ }^{1}$ Schinzel A. Autosomal chromosomal. Archiv Für Genetik (Zurich) 1979;52:1-204. \\ 2 Leisti J, Leisti S, Perheentupa J, Savilahti E, Aula P. Absence of IgA and growth hormone deficiency associated with short arm deletion of chromosome 18. Arch Dis Child 1973;48:320-2. \\ ${ }^{3}$ Buffoni L, Tarateta A, Aicandi G, et al. Nanismo ipofisario e sindrome malformativa multipla "tipo Goldenhar" in soggetto con delezione del braccio del cromosoma 18. Minerva Pediatr 1976;28:716-29. \\ ${ }^{4}$ Grouchy J De. The $18 p-, 18 q-$ and $18+$ syndromes in birth defects. Original Article Series, Vol V. The clinical delineation of birth defects. Part V. Phenotypic aspects of chromosomal abbreviations. National Foundation-March of Dimes, Baltimore: Williams and Wilkins, 1969:74-87. \\ 5 Chustensen KR, Friedrich U, Jacobsen P, et al. Ring chromo- some 18 in mother and daughter. J Ment Defic Res 1970;14: 49-67.}

Correspondence to Dr DCL Savage, Bristol Royal Hospital for Sick Children, St Michael's Hill, Bristol BS2 8BJ.

Accepted 21 January 1988

\title{
Glaucoma as an early complication of Hurler's disease
}

\author{
M J NOWACZYK, J T R CLARKE, ${ }^{*}$ AND J D MORIN $\dagger$ \\ Departments of Paediatrics, *Genetics, and †Ophthalmology, Hospital for Sick Children and University of \\ Toronto, Toronto, Canada
}

\begin{abstract}
SUMMARY We report three cases of Hurler's disease in which glaucoma developed in early childhood. We draw attention to the fact that glaucoma may be a commonly unrecognised early complication of this condition.
\end{abstract}

Glaucoma has been reported as a complication of mucopolysaccharide (MPS) storage diseases in adults with milder variants, such as Scheie disease (MPS IS). ${ }^{1}$ A single case of glaucoma in a child with Hurler's disease (MPS IH) was reported by Spellacy et $a .^{2}$ The authors speculated that glaucoma only develops late in milder forms of MPS storage diseases, and is rarely seen in patients with MPS IH because of their short life expectancy.

\section{Case reports}

CASE 1

A girl, weighing $3886 \mathrm{~g}$, was born at term to nonconsanguinous black parents. Noisy breathing and snoring were reported from early infancy. There was initially mild, but subsequently more severe and progressive, developmental delay. Congenital glaucoma was suspected at 16 months of age because of corneal clouding. At 18 months of age, she had many characteristic clinical features of MPS storage, including large head $(49.0 \mathrm{~cm},>98$ th percentile), depressed nasal bridge, thick lips, large tongue, dysplastic teeth, hepatosplenomegaly, and a mild gibbus and flaring of the lower ribcage. Radiographic examination of the skeleton showed changes typical of Hurler's disease (MPS IH). The diagnosis was confirmed by the demonstration of absence of $\alpha$ iduronidase in leucocytes and cultured skin fibroblasts.

Pronounced corneal opacities were noted on examination. Examination under anaesthesia showed corneal diameters of $12.25 \mathrm{~mm}$ in the left eye and $12.50 \mathrm{~mm}$ in the right eye. Pressure was $3.07 \mathrm{kPa}$ in the right eye, and $3.20 \mathrm{kPa}$ in the left. There was 
central cupping of optic disks with cup/disk ratio of 0.4 in both eyes. The cups were vertically elongated. A right and left goniotomy was performed, and pilocarpine $4 \%$ and chloramphenicol/hydrocortisone/polymyxin B ointment were instilled. The postoperative course was uneventful.

\section{CASE 2}

A boy, born prematurely at 37 weeks' gestation weighing $2040 \mathrm{~g}$, had his neonatal course complicated by the development of hyaline membrane disease, which progressed to bronchopulmonary dysplasia. He had recurrent colds and otitis media throughout infancy. Bilateral inguinal hernia repairs were required twice because of recurrence. Developmental milestones lagged behind the normal. At 16 months of age he developed persistent tearing and photophobia in both eyes. At 18 months a diagnosis of congenital glaucoma was made. On examination, bilateral corneal opacities and the characteristic clinical features of Hurler's disease were noted. The diagnosis of MPS I was confirmed by the demonstration of deficiency of $\alpha$ iduronidase in peripheral blood leucocytes.

On examination under anaesthesia corneal diameters were $12.75 \mathrm{~mm}$ in the right eye and $12.00 \mathrm{~mm}$ in the left eye. Both corneas were extremely cloudy, making ophthalmoscopy very difficult, especially in the left eye. Optic disks were pale with a cup/disk ratio of about $0 \cdot 6-0 \cdot 7$. The intraocular pressures were $1.60 \mathrm{kPa}$ in the left and $3.07 \mathrm{kPa}$ in the right eye. With the aid of a Barkan lens, bilateral goniotomies were performed without difficulty. pilocarpine $4 \%$ and chloramphenicol/ hydrocortisone/polymyxin B ointment were instilled into both eyes; the postoperative course was uneventful.

\section{CASE 3}

A girl was born at term and developed normally until the age of 5 months. She was referred at the age of 7 months by her family physician for investigation of recurrent upper respiratory infec- tions, macrocephaly, hepatosplenomegaly, and recent developmental delay. On examination, she was $69 \mathrm{~cm}$ in height (90th percentile), weighed $8.48 \mathrm{~kg}$ (75th percentile); head circumference was $50 \mathrm{~cm}$ (>98th percentile). The typical facial appearance and other clinical features of Hurler's disease were noted. The diagnosis of MPS I was confirmed by the demonstration of absent $\alpha$ iduronidase activity in peripheral blood leucocytes.

Examination under anaesthesia at the age of 17 months showed corneal diameters of $12.25 \mathrm{~mm}$ bilaterally and normal fundi. There was no evidence of papilledema or increased intraocular pressures. Slight corneal opacities were noted bilaterally. At 5 years of age, she again underwent examination under anaesthesia because of decrease in visual acuity. By that time corneal opacities had increased appreciably; however, the details of the irides could still be discerned. Corneal diameters were $12.5 \mathrm{~mm}$ bilaterally. The intraocular pressures measured $3.73 \mathrm{kPa}$ in the right and $4.00 \mathrm{kPa}$ in the left eye by applanometer tonometry. Diagnosis of glaucoma was made, and treatment with pilocarpine drops was started.

\section{Discussion}

Glaucoma is a well recognised, but apparently rare, complication of MPS storage diseases; as a presenting problem it is virtually unknown. In two of the three cases reported here, however, the diagnosis of a storage disorder had not been made when glaucoma developed before the age of 5 years. The eye complaints were typical: excessive tearing, photophobia, and clouding of the corneas (table). Although characeristic also of glaucoma, the clouding of the corneas in these cases was attributable primarily to MPS storage. The diagnosis of glaucoma was supported by the demonstration of increased corneal diameters, cup/disk ratios greater than $0 \cdot 3$, and the presence of increased intraorbital pressures (table). In one case the patient improved with medical treatment alone; in the other two goniotomies were performed.

Table Ocular findings in patients

\begin{tabular}{|c|c|c|c|c|c|}
\hline $\begin{array}{l}\text { Case } \\
\text { No }\end{array}$ & Presenting symptoms & Eye & $\begin{array}{l}\text { Corneal } \\
\text { diameters } \\
(\mathrm{mm})\end{array}$ & $\begin{array}{l}\text { Intraocular } \\
\text { pressure } \\
(k P a)\end{array}$ & $\begin{array}{l}\text { Disk/cup } \\
\text { ratio }\end{array}$ \\
\hline 1 & Corneal opacities & $\begin{array}{l}\text { Right } \\
\text { Left }\end{array}$ & $\begin{array}{l}12 \cdot 50 \\
12 \cdot 25\end{array}$ & $\begin{array}{l}3 \cdot 07 \\
3 \cdot 20\end{array}$ & $\begin{array}{l}0.4 \\
0.4\end{array}$ \\
\hline 2 & $\begin{array}{l}\text { Redness of the eye } \\
\text { Photophobia, excessive tearing }\end{array}$ & $\begin{array}{l}\text { Right } \\
\text { Left }\end{array}$ & $\begin{array}{l}12 \cdot 75 \\
12 \cdot 00\end{array}$ & $\begin{array}{l}3 \cdot 07 \\
1 \cdot 60\end{array}$ & $\begin{array}{l}0.6-0.7 \\
0.6-0.7\end{array}$ \\
\hline 3 & Decrease in visual acuity & $\begin{array}{l}\text { Right } \\
\text { Left }\end{array}$ & $\begin{array}{l}12 \cdot 50 \\
12 \cdot 50\end{array}$ & $\begin{array}{l}3 \cdot 73 \\
4 \cdot 00\end{array}$ & Not examined \\
\hline
\end{tabular}


The most common cause of infantile glaucoma is interference with aqueous outflow caused by arrest of the development of the trabecular meshwork of the anterior chamber angle. In MPS storage diseases, the trabecular meshwork becomes engorged and distorted by accumulating MPS, which also causes thickening of the extracellular matrix in sclera and corneas, resulting in further constriction of the anterior chambers. ${ }^{34}$ Distortion of the meshwork in the corneoscleral junction and adjacent to the canal of Schlemm interferes with the flow of aqueous humour through the endothelial lining. ${ }^{5}$ The presence of incompletely degraded MPS in the outflow apparatus is also thought to inhibit hyaluronidase and other degradative enzymes involved in the maintenance of normal aqueous outflow. ${ }^{6}$

Glaucoma may be a more common early complication of Hurler's disease than has been previously appreciated. The recognition of the complication is undoubtedly obscured by the fact that one of the principal clinical features of glaucoma in infants-corneal clouding-is also a prominent finding in Hurler's disease. Corneal opacification in infantile glaucoma is due to aqueous entering corneal stroma via microscopic breaks in Descemet's membrane resulting from increased intraocular pressure. The separations are permanent and appear as wavy parallel lines-usually curvilinear and horizontal, on the inner side of the cornea. In Hurler's syndrome the avascular noninflammatory corneal clouding is a result of lysosomal engorgement with MPS material. Here, fine grey punctate opacities are first seen in the anterior stroma, then in the posterior stroma and endothelium. Clinically, however, these two types of corneal clouding are undistinguishable. Early recognition and treatment of the glaucoma would not be expected to contribute appreciably to the longevity of children with Hurler's disease; however, it clearly enhances the quality of life of affected patients. Physicians attending patients with MPS disorders should be alert to the possibility of the problem occurring, and obtain appropriate ophthalmological consultation should ocular complaints possibly attributable to glaucoma develop.

This work was supported in part by a summer student scholarship provided to one of us (MJN) by the MPS Society of Canada.

\section{References}

1 Quigley HA, Maumenee E, Stark WJ. Acute glaucoma in systemic mucopolysaccharidosis I-S. Am J Ophthalmol 1975;80: 70-2.

2 Spellacy E, Kennerley Bankes JL, Crow J, Dourmashkin R, Shah D, Watts RWE. Glaucoma in a case of Hurler disease. Br J Ophthalmol 1980;64:773-8.

${ }^{3}$ Muenzer J. Mucopolysaccharidoses. Adv Pediatr 1986;33: 269-302.

4 Tripathi RC, Ashton N. Application of electron microscopy to the study of ocular inborn errors of metabolism. Birth Defects 1976;12:69-104.

5 Tripathi RC. Mechanism of the aqueous outflow actoss the trabecular wall of Schlemm's canal. Exp Eye Res 1971;11: 116-21.

${ }^{6}$ Paterson WS, Jackson VL. Hyaluronidase effects on aqueous outflow resistance. Am J Ophthalmol 1974;77:573-7.

Correspondence to Dr JTR Clarke, Division of Clinical Genetics, Hospital for Sick Children, 555 University Avenue, Toronto, Ontario, Canada M5G 1X8.

Accepted 6 May 1988 